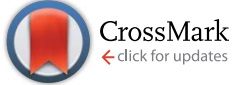

Cite this: RSC Adv., 2015, 5, 19659

\title{
Humidity assisted annealing technique for transparent conductive silver nanowire networks $\uparrow$
}

\author{
Nelli Weiß, ${ }^{\text {a }}$ Lars Müller-Meskamp, ${ }^{\mathrm{b}}$ Franz Selzer, ${ }^{\mathrm{b}}$ Ludwig Bormann, ${ }^{\mathrm{b}}$ \\ Alexander Eychmüller, ${ }^{a}$ Karl Leo ${ }^{b}$ and Nikolai Gaponik ${ }^{* a}$
}

The surfactant polyvinylpyrrolidone (PVP) commonly used to synthesize silver nanowires (AgNW) in solution is known to negatively affect the performance of nanowire-based thin film electrodes. An insulating shell of the polymer hinders tight contact between the nanowires themselves and between the nanowires and substrate, resulting in high sheet resistance of the freshly prepared nanowire films. Here, we develop a simple low-temperature method allowing us to reduce the sheet resistance of AgNW networks and simultaneously improving the optical transmittance. The method is based on the capacity of PVP to absorb moisture which results in a strong decrease in the glass transition temperature of the polymer. The latter leads to softening effects, causing a reduced wire contact resistance already at $60{ }^{\circ} \mathrm{C}$ for 90 $\mathrm{nm}$ thick AgNWs and even at $45{ }^{\circ} \mathrm{C}$ for $35 \mathrm{~nm}$ thick AgNWs. As a result, the sheet resistances of the thin film electrodes treated by our method are near to the values conventionally obtained after thermal annealing at temperatures between $140-250{ }^{\circ} \mathrm{C}$. Our humidity assisted low temperature approach is especially advantageous for organic electronics and fabricating devices on thermally sensitive transparent flexible foils.

Received 22nd January 2015 Accepted 6th February 2015

DOI: $10.1039 / \mathrm{c} 5 \mathrm{ra0} 1303 \mathrm{~h}$

www.rsc.org/advances

to provide the nanowire shape, its stability and dispersibility in water or alcohols. ${ }^{\mathbf{1 4 , 1 5}}$ Hence, after deposition on a substrate, the contacts between individual NWs are deteriorated by the insulating PVP shell inducing a barrier for electron transport. ${ }^{16-18}$ As a result, an additional step is required to reduce the junction resistance between individual AgNWs and to obtain high conductivity of electrodes. In the case of silver, well-conducting NW arrays were produced by applying mechanical pressure, ${ }^{19-21}$ by thermal, ${ }^{17,22-26}$ nanoplasmonic ${ }^{11,27}$ or Joule ${ }^{28}$ annealing. Additional improvement approaches include the fabrication of hybrid materials with polymers, ${ }^{\mathbf{1 3 , 2 9}}$ metal $^{30}$ or oxide ${ }^{31,32}$ nanoparticles as well as carbon nanotubes $^{33}$ and graphene sheets. ${ }^{34-37}$ Most of these strategies are time- and energy-consuming, involve special complex equipment and exotic nanomaterials. Because of its simplicity, thermal annealing at $140-250{ }^{\circ} \mathrm{C}$ remains the most favored method for decreasing the sheet resistance of AgNW films. ${ }^{9,23,29,31,38}$ However, the utilization of thermal annealing is restricted in the case of organic electronics and especially for flexible substrates. Most of the known plastic foils used for the fabrication of flexible devices tend to deform at processing temperatures above $120{ }^{\circ} \mathrm{C} \cdot{ }^{39-42}$

In our work the moisture induced reduction of the glass transition temperature of PVP is proposed as a technique to allow annealing of AgNW electrodes at low temperatures. We show that the exposition of NW network electrodes to water vapor at $60{ }^{\circ} \mathrm{C}$ for $90 \mathrm{~nm}$ thick AgNWs and even at $45^{\circ} \mathrm{C}$ for $35 \mathrm{~nm}$ thick AgNWs causes a considerable decrease in their sheet resistance. At the

${ }^{a}$ Physical Chemistry, TU Dresden, Bergstraße 66b, Dresden, D-01062, Germany. E-mail:nelli.weiss@chemie.tu-dresden.de; nikolai.gaponik@chemie.tu-dresden.de D-01062, Germany

$\dagger$ Electronic supplementary information (ESI) available: Changes in total transmittance $\Delta T v$ s. initial total transmittance; transmittance spectra of NW-35 electrode $v s$. annealing time; SEM images of a NW-35 electrode on glass; sheet resistance $v s$. annealing time at a constant temperature of $60{ }^{\circ} \mathrm{C}$ and different RH values; SEM image, transmittance and reflectance spectra of NW-90 electrode on PEN foil. See DOI: 10.1039/c5ra01303h 
same time, the total optical transmittance of the NW electrodes could be enhanced. Conducting films on glass, PEN and PET substrates were investigated.

\section{Experimental}

Experiments were performed on cleaned $2.5 \times 2.5 \mathrm{~cm}^{2}$ BK7 glass substrates (Schott, Mainz, Germany), polyethylene terephthalate (PET) foil (Melinex ST504, DuPont Teijin Films) or polyethylene naphthalate (PEN) foil (Teonex Q65F, DuPont Teijin Films) treated by oxygen plasma and cleaned with the contact cleaner "Nanocleen" (Teknek Ltd, Renfreshwire, UK). Silver nanowires SLV-NW-90 (mean diameter $90 \mathrm{~nm}$, mean length $25 \mu \mathrm{m}$ ) and SLV-NW-35 (mean diameter $35 \mathrm{~nm}$, mean length $10 \mu \mathrm{m}$ ) were purchased from BlueNano, USA. These samples are referred in the following as NW-90 and NW-35, respectively. The as received dispersions were diluted with ethanol to a concentration of $0.2 \mathrm{mg} \mathrm{ml}^{-1}$, sonicated for $15 \mathrm{~min}$ and then spray-coated with a nozzle (Fisnar, Wayne (NJ), USA) onto a heated substrate at $80{ }^{\circ} \mathrm{C}$. The spraying distance, moving speed and spraying pressure of the nozzle were $12 \mathrm{~cm}, 1.5 \mathrm{~cm} \mathrm{~s}^{-1}$ and 200 mbar, respectively.

Following the spray deposition, the electrodes were exposed in a climate cabinet (Thermo Tec) at temperatures between $45{ }^{\circ} \mathrm{C}$ and $85{ }^{\circ} \mathrm{C}$ to a relative humidity $(\mathrm{RH})$ of between $15 \%$ and $85 \%$ for $24 \mathrm{~h}$ or 3 days for long-term experiments. During these experiments the samples were taken out of the climate cabinet several times for electrical and optical characterization for about 15 minutes a time. To exclude effects of residual water on the conductivity, an additional annealing step $\left(10 \mathrm{~min}\right.$ at $105^{\circ} \mathrm{C}$ on a hot plate) was applied after removing the samples from the climate cabinet and before measuring the sheet resistance of the electrodes. Because a significant difference of the sheet resistance values before and after the additional drying was not observed, all later experiments were performed without additional annealing. Reference electrodes were fabricated by annealing as sprayed electrodes 30 minutes at $210{ }^{\circ} \mathrm{C}$ on a hot plate under ambient laboratory conditions: $23{ }^{\circ} \mathrm{C}$ and $48 \%$ humidity.

Transmittance and reflectance measurements were performed using a UV-VIS spectrometer with an integrating sphere (Shimadzu). The data reported in this work include transmittance and reflectance of the corresponding glass or plastic substrate. Direct transmittance was acquired by placing the samples perpendicular to the incident light in the spectrometer. Total transmittance was acquired using the integrating sphere setup. To measure the reflectance spectra an integrating sphere and an illumination angle of 5 degree were used. All optical transmission and reflection values are quoted at $\lambda=550 \mathrm{~nm}$. A four point probe setup (Lucas Labs) was used for measuring the sheet resistance. Scanning electron microscopy (SEM) images were taken with a Carl Zeiss DSM 982 Gemini electron microscope.

\section{Results and discussion}

In this work two different AgNW diameters were chosen as representative examples of widely used materials in the field. Transparent conductive electrodes based on NW-90 or NW-35 vary in uniformity, roughness, thermal stability, transparency at a given sheet resistance and haze value. The AgNWs were sprayed onto a glass substrate from ethanol solutions and then kept in the climate cabinet for 24 hours. The temperature was varied in the range from 45 to $85^{\circ} \mathrm{C}$, the relative humidity from 15 to $85 \%$. As these AgNW films were developed for transparent conducting electrode applications, optical spectra and sheet resistances were measured at different time intervals. A typical alteration of optical transmittance spectra of the NW-90 electrode during humidity assisted annealing is shown in Fig. 1a. Unexpectedly, both direct $\left(T_{\text {direct }}\right)$ and total transmittances $\left(T_{\text {total }}\right)$ increased during this treatment. The main changes happen within the first $30 \mathrm{~min}$ of the treatment. Further changes in the optical spectra appeared slowly, depending on the temperature applied and the $\mathrm{RH}$ value. The difference between the initial and the final values of the total
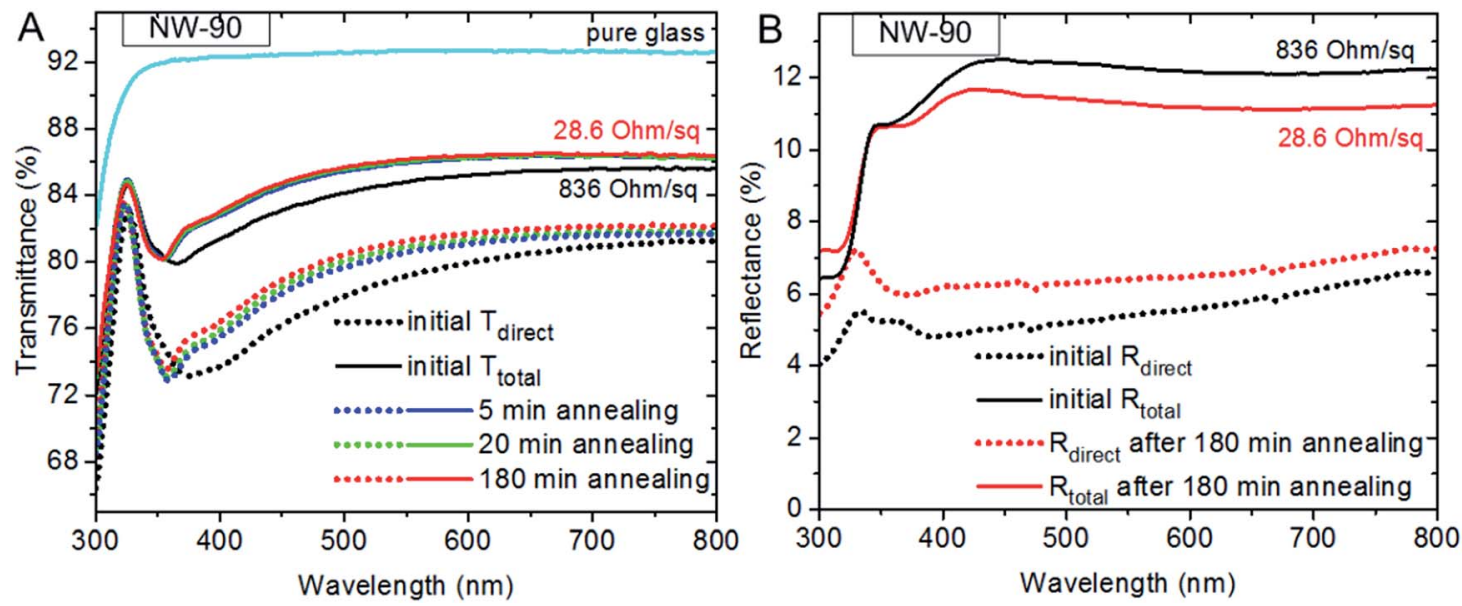

Fig. 1 (A) Total transmittance spectra of pure glass substrate (the same before and after annealing) as well as total and direct transmittance spectra of an NW-90 electrode heated at $85^{\circ} \mathrm{C} / 85 \% \mathrm{RH}$. (B) Total and direct reflectance spectra of the same NW-90 electrode before and after annealing at $85^{\circ} \mathrm{C} / 85 \% \mathrm{RH}$. 
transmittances is found to especially depend on the NWs density and not on the annealing conditions of the electrode (Fig. S1 $\dagger$ ). For example, an electrode with an initial $T_{\text {total }}$ of $77 \%$ showed a $T_{\text {total }}$ of $81 \%$ after annealing, giving $4 \%$ difference from the initial value. An initial $T_{\text {total }}$ of $85 \%$ could be enhanced only for about $1 \%$. An electrode with an initial $T_{\text {total }}$ of $88 \%$ became only $0.2 \%$ more transparent after annealing.

An increase of the total transmittance of the electrode can occur due to the changes in scattering behavior of the NW film after annealing. Total and direct reflectance spectra of a NW-90 electrode on glass before and after annealing are shown in Fig. 1b. After annealing, the direct reflectance increased and the total reflectance dropped, indicating a lower scattering of the electrode. The decrease in total reflectance approximately corresponds to the increase in total transmittance. The strong relative increase in direct reflection and less diffuse transmission indicate the film is becoming more planar and less particle-like. This can be well explained by changes in the
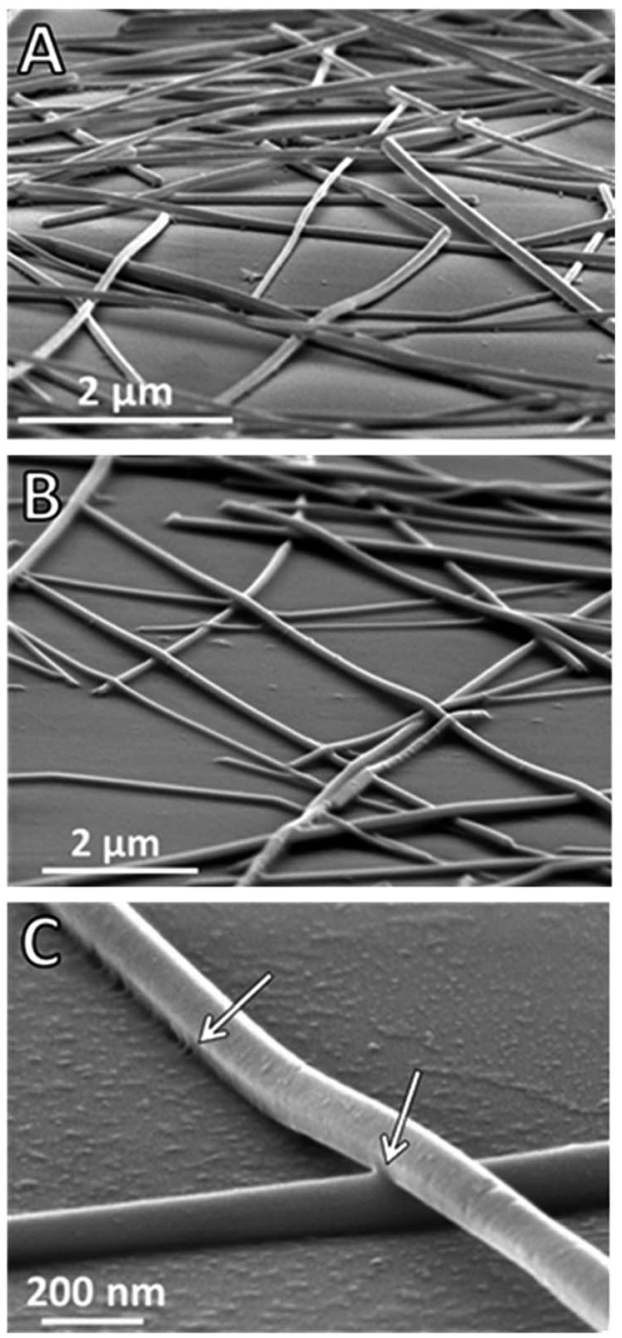

Fig. 2 SEM images of Ag90-NW directly after spraying (A), after 180 min annealing at $85{ }^{\circ} \mathrm{C} / 85 \% \mathrm{RH}$ (B) and $85{ }^{\circ} \mathrm{C} / 70 \% \mathrm{RH}$ (C) demonstrating changes in the morphology of the NW networks. White arrows in (C) highlight the closer alignment of the wires and a better contact to the substrate. electrode morphology before and after annealing. Comparing Fig. 2a and b, where NW-90 before and after annealing at $85^{\circ} \mathrm{C} / 85 \% \mathrm{RH}$ are shown, one can see a softening of the wires, resulting in their slight shape deformation and a closer alignment to each other. Additionally, humidity treated wires have conformal contact to the substrate. Both closer alignment and contact to the substrate are highlighted with white arrows in the higher resolution image shown in Fig. 2c.

Alterations in the optical spectra of the NW-35 films at different annealing times are shown in Fig. $\mathbf{S} 2 . \dagger$ Both, changes in the maximum of the transmission spectrum as well as in the value of the transmittance were monitored. Similar to thicker NWs, humidity assisted annealing at RH below 85\% leads to relatively compacter films with better contacts between crossing wires, as shown in the corresponding SEM images in Fig. S3. $\dagger$

Comparing optical data for both types of NWs with their SEM images one may conclude that the observed formation of a denser NW network leads to a lower light scattering and as a result to an increased total transmittance of the electrode.

The changes in film morphologies described above have a direct influence on the electrical properties of NW-90 electrodes. Fig. 3a shows the temporal evolution of their sheet resistance $\left(R_{\mathrm{S}}\right)$ during annealing at $85{ }^{\circ} \mathrm{C}$ and $85 \%$ RH. As seen from the figure, the resistance of the electrodes decreased considerably already after the first 30 minutes of the treatment, regardless of the coverage. The highest change of the sheet resistance was observed for samples with the lowest NW density (Fig. 3a). For example, the sheet resistance of the sample with an initial $T_{\text {total }}$ of $84 \%$ dropped from $836 \mathrm{Ohm} \mathrm{sq}^{-1}$ to $28.6 \mathrm{Ohm}$ $\mathrm{sq}^{-1}$ (ca. 30 times!) after $180 \mathrm{~min}$. For the sample with $75 \% T_{\text {total }}$ the sheet resistance decreased from $9.5 \mathrm{Ohm} \mathrm{sq}^{-1}$ to $4.3 \mathrm{Ohm}$ $\mathrm{sq}^{-1}$ (ca. 2.2 times only). Taking into account that the junction resistance is the most dominant component in the sheet resistance of the networks with a smaller wire number density closer to the percolation threshold ${ }^{\mathbf{4 3 , 4 4}}$ and becomes less pronounced at high coverages, one can assume that the humid annealing reduces the junction resistance between crossing NWs. For deeper investigation of this phenomenon, solely NW networks with relatively low wire densities, i.e. with initial total transmittances between 81 and $84 \%$ for NW-35 networks and between 84 and $87 \%$ for NW-90 networks and, thus, expected higher conductivity improvement factors were chosen for further studies.

The temporal evolution of the sheet resistance of NW-90 electrodes as a function of humidity is displayed in Fig. 3b, c and $\mathrm{S} 4 \mathrm{a} . \dagger$ At the highest $\mathrm{RH}$ value of $85 \%$ a considerable decrease in the sheet resistance of the electrode was detected already at $60{ }^{\circ} \mathrm{C}$ (green line in Fig. 3b). If the temperature was kept constant, faster changes were observed at higher $\mathrm{RH}$ values (Fig. 3c and S4a†). At $85{ }^{\circ} \mathrm{C}$ and $\mathrm{RH}$ of 85 or $70 \%$ the sheet resistance dropped to the final value within $30 \mathrm{~min}$ of annealing. At $50 \% \mathrm{RH}$ about 2 hours were necessary to achieve the minimum value of the film sheet resistance. At 30\% and 15\% $\mathrm{RH}$ a continuous decrease of film resistivity was detected during 24 hours of measurement. Almost the same dependence of $R_{\mathrm{S}}$ from moisture content was observed for NW-35 networks (Fig. 4 and $\mathrm{S} 4 \mathrm{~b} \dagger$ ). Only at the highest investigated $\mathrm{RH}$ value of $85 \%$ a 

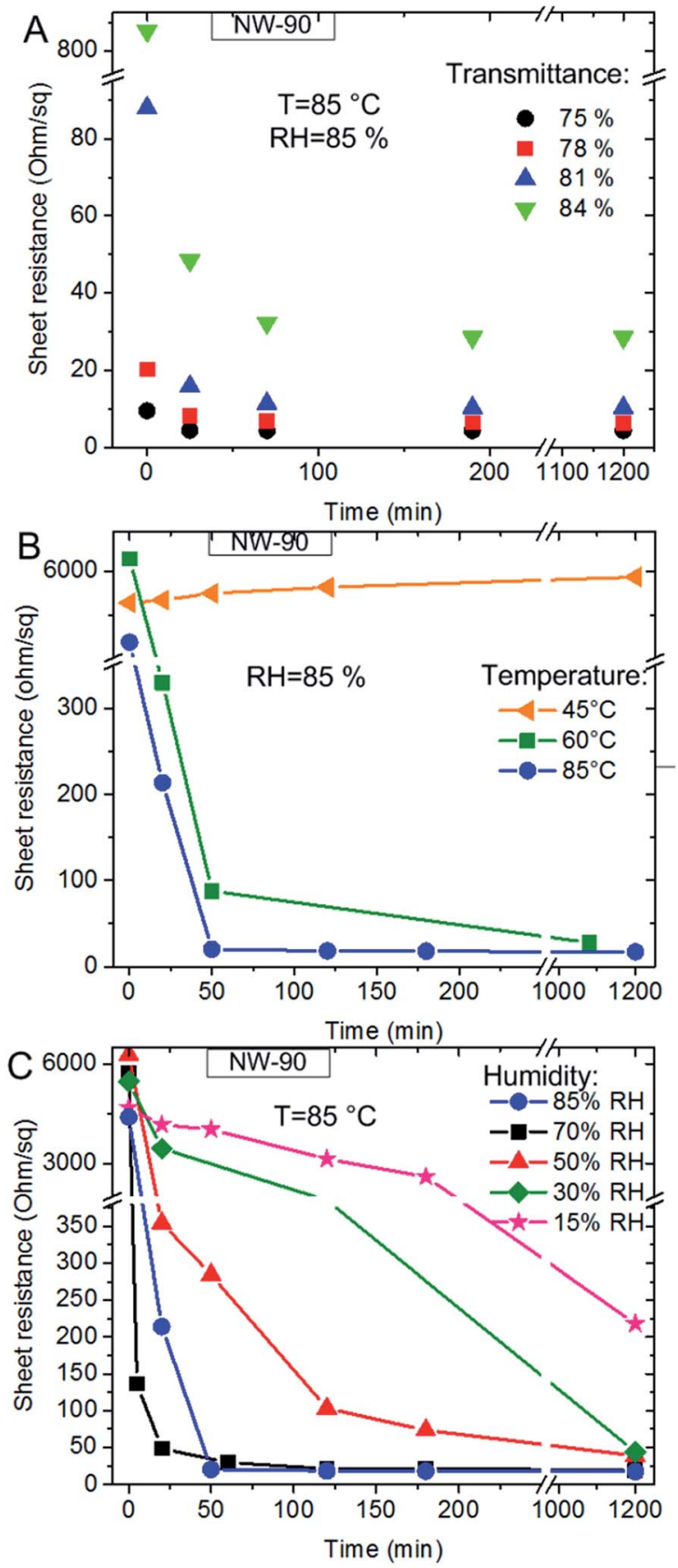

Fig. 3 Sheet resistance vs. annealing time for NW-90 films: (A) at different coverages during annealing at $85{ }^{\circ} \mathrm{C}$ and $85 \% \mathrm{RH}$; (B) at constant $\mathrm{RH}$ of $85 \%$ and different temperatures; and (C) at constant temperature of $85{ }^{\circ} \mathrm{C}$ and different $\mathrm{RH}$ values. The blue line representing the sample treated under $85^{\circ} \mathrm{C} / 85 \% \mathrm{RH}$ is the same in both $\mathrm{B}$ and $C$ frames.

considerably different behavior of NW-90 and NW-35 was observed. At $85{ }^{\circ} \mathrm{C} / 85 \% \mathrm{RH}$ the sheet resistance of the electrode with thinner NWs (blue line in Fig. 4a and b) decreases within the first $120 \mathrm{~min}$ of annealing but started to increase gradually thereafter. The reason of this unexpected behavior is the damaged NW network as seen from the SEM image in Fig. S3d. $\dagger$ Obviously, after longer humidity assisted annealing of NW-35 films, the small diameter wires collapse and melt into
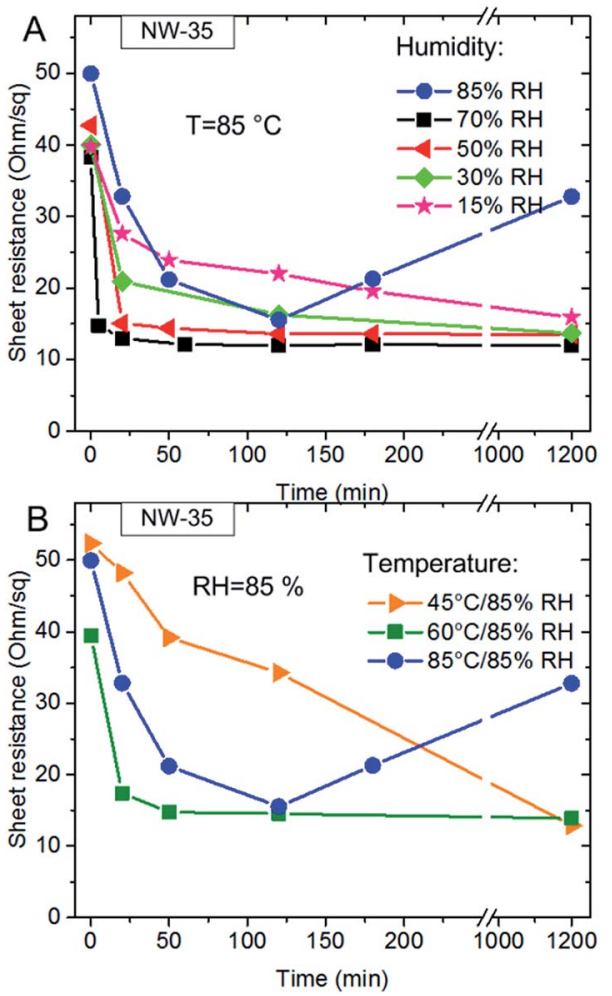

Fig. 4 Sheet resistance vs. annealing time for AgNW-35 films: (A) at constant temperature of $85^{\circ} \mathrm{C}$ and different $\mathrm{RH}$ values; (B) at constant $\mathrm{RH}$ of $85 \%$ and different temperatures. The blue line represents the sample treated under $85^{\circ} \mathrm{C} / 85 \% \mathrm{RH}$ similarly in both frames.

spherical particles disconnecting the NW network. Moreover, as shown in Fig. S3c, $\uparrow$ some spherical particles were already found after annealing of the NW-35 films at $85 \% \mathrm{RH}$ and $60^{\circ} \mathrm{C}$. But in this case the percolation NW network was not destroyed completely and $R_{\mathrm{S}}$ of the electrode remained low (Fig. $4 \mathrm{~b}$, green line).

The results presented in Fig. 5 compare the performance of NW-90 electrodes obtained after the humidity assisted annealing $\left(85^{\circ} \mathrm{C} / 70 \% \mathrm{RH}\right)$ introduced in this work with the same electrodes treated by conventional high temperature annealing on a hot plate at $210^{\circ} \mathrm{C}$, under ambient, i.e. low humidity. For both conditions, nearly the same final values of film sheet resistances were reached demonstrating the potential of our low temperature approach.

The results discussed above allow us to propose the following mechanism for the observed phenomena. Thermal annealing of the AgNW network is known to be accompanied with the softening and flowing of PVP. ${ }^{17,26}$ The point at which polymers become rubbery occurs at the glass transition temperature $\left(T_{\mathrm{g}}\right)$ and depends on the molecular weight of the polymers as well as on the moisture content. PVP is hygroscopic so that it tends to absorb large amounts of water vapor. The extent of water, which acts as a plasticizer agent, increases continuously with relative humidity, leading to a lowering of the $T_{\mathrm{g}}$ to even below room temperature. ${ }^{45-48}$ Hence, under humidity assisted annealing in our experiments the PVP shell on the NWs could easyly absorb water, melt and flow away from the NW at as 


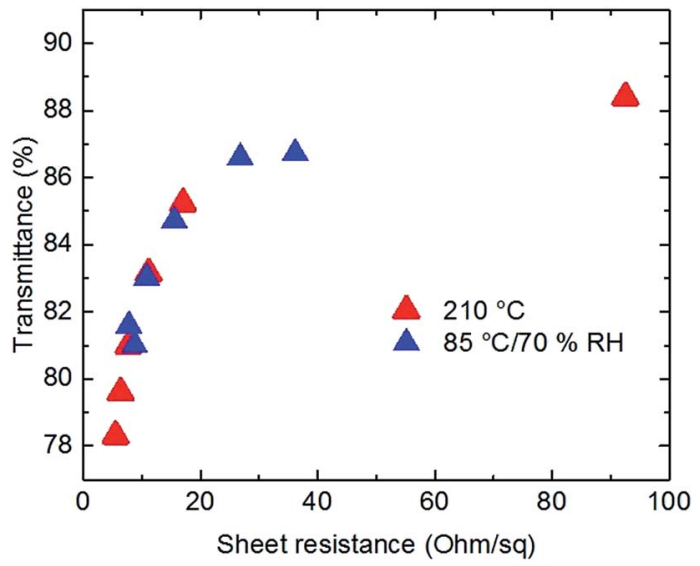

Fig. 5 Plot of total transmittance at $550 \mathrm{~nm}$ vs. sheet resistance for NW-90 films heated for $90 \mathrm{~min}$ at $210{ }^{\circ} \mathrm{C}$ on a heating plate (red triangles) and that of films treated for $120 \mathrm{~min}$ at $85^{\circ} \mathrm{C} / 70 \% \mathrm{RH}$ in a climate chamber (blue triangles)

low temperatures as $85{ }^{\circ} \mathrm{C}, 60{ }^{\circ} \mathrm{C}$ and even $45^{\circ} \mathrm{C}$. As a consequence the following effects might be expected:

(i) As was already mentioned above, the originally rigid wires become softer at higher humidity. This effect is well known in hair care cosmetics, where PVP and its copolymers are used as hair sealer. ${ }^{49-51}$ PVP easily forms films between styled hairs. Nevertheless, these films cannot hold styled hair long in place because of the hygroscopic character of PVP leading to its softening. Therefore, copolymers of PVP containing the less hydrophilic vinyl acetate or $N$-vinylcaprolactam chains are used in modern moisture resistance hair sprays. ${ }^{49}$ In our experiments, however, the ability of PVP to adsorb water shows a positive effect on the final electrode properties of both, NW-35 and NW-90 wires. Softening of the wet PVP shell allows elastic alignment of the NWs and thereby improves the electrical contact area between crossing wires.

(ii) Softened by moisture absorption, the rubbery PVP chains of the contacting wires can effectively intercalate ${ }^{52}$ and interact hydrophobically with each other and the surface. Moreover, softened and melted PVP is flowing down from the top and the side surfaces of the NWs and accumulates below the NWs causing an effective adhesion force, resulting in a tighter contact between crossing NWs and between the NWs and the substrate (marked by white arrows in Fig. 2c). Similar phenomena observed for AgNWs treated by various polymers and surfactants were investigated and described by us in detail in our recent publication. ${ }^{53}$ This reorganization of PVP on the AgNWs causing a tighter adhesion to the substrate yields a more planar film which is responsible for a reduced scattering cross section and for an increased optical transmission of the electrodes. Such kind of the PVP shell reorganization, e.g. softening, flowing and accumulation below the NWs may also happen under annealing above the glass transition temperature in ambient conditions.

(iii) A partial removal of PVP from the NWs during the annealing might open free paths for surface diffusion of silver atoms and the formation of joints between two contacting wires at a relatively low temperature. Such kind of low temperature sintering was earlier demonstrated for plasma etched AgNWs by Zhu et al. ${ }^{54}$ Moreover Peng et al. describe a room temperature soldering of copper with AgNW paste after intensive reduction of the organic shell by washing. ${ }^{55}$ Although we expect soldering effects also in our experiments, this was observed solely for some of the wire joints in NW-35 electrodes (white arrows in Fig. $\mathrm{S} 3 \mathrm{~b} \dagger$ ). If more intensive and prolonged humidity assisted annealing is applied to NW-35 it does not lead to further soldering but to breaking and deformation of the wires into spherical particles due to Raleigh instability ${ }^{27,56}$ (Fig. S3c and $\mathrm{d} \dagger)$. Most likely in these thin wires with relatively higher surface energy morphological changes happen faster than the expected soldering. At the same time, for annealed samples of NW-90 neither deforming nor soldering effects are visible even after 3 days in humidity. The observed decrease of sheet resistance may mainly be attributed to closer contacts formed according to the effects described in (i) above.

The humidity assisted annealing technique presented in this work can be advantageous for fabrication of NW electrodes on thermally sensitive plastic substrates for which annealing over $120^{\circ} \mathrm{C}$ is not favourable. For a demonstration the approach was applied to AgNW electrodes spayed onto two types of plastic foil, PET and PEN. As exemplarily shown in Fig. S5a and b, $\uparrow$ the total optical transmittance of NW-90 electrodes formed on PEN increased after annealing accompained with a decrease in total reflectance. At the same time the initial sheet resistance of the electrodes was effectively reduced from $406 \mathrm{Ohm} \mathrm{sq}^{-1}$ to 17.8 $\mathrm{Ohm} \mathrm{sq}^{-1}$. The same behaviour was observed for PET based electrodes (not shown here). Final sheet resistance values of $17.8 \mathrm{Ohm} \mathrm{sq}^{-1}$ at $81.8 \%$ transmittance on PEN and $16.1 \mathrm{Ohm}$ $\mathrm{sq}^{-1}$ at $80.9 \%$ transmittance on $\mathrm{PET}$ were achieved. It is important to note, that these performances are comparable with literature data for AgNWs on PET and PEN obtained by pressing or annealing under much more sophisticated conditions. ${ }^{11-13,19-21,23,27,43,54,56-67}$

It should be mentioned that humidity treatment should be applied to NW electrodes for as short time as possible. Recent results $^{68}$ show that long term (months) of humidity treatment may cause degradation of the AgNWs electrodes.

\section{Conclusions}

In summary, we demonstrated a new low temperature technique allowing a fast and efficient reduction of the contact resistance between AgNWs forming transparent conducting electrodes. The technique is based on reducing the glass transition temperature of the PVP stabilizer by increasing the humidity. As a result, softening of PVP, improved alignment and better contact between the AgNWs in the film can be achieved at temperatures as low as $45-85{ }^{\circ} \mathrm{C}$. The performance of humidity assisted annealed electrodes are comparable with typical literature results obtained after conventional high temperature annealing. The great advantage of our simple and straightforward method is its direct applicability to flexible polymer substrates. 


\section{Acknowledgements}

The authors gratefully acknowledge Susanne Goldberg from TU Dresden for the SEM measurements and David Kneppe for spraying the AgNW films. The research leading to these results has received funding from the European Union Seventh Framework Program (FP7/2007-2013) under grant agreement no. 314068.

\section{Notes and references}

1 S. Kumar, B. a. Cola, R. Jackson and S. Graham, J. Electron. Packag., 2011, 133, 020906.

2 D. Langley, G. Giusti, C. Mayousse, C. Celle, D. Bellet and J.-P. Simonato, Nanotechnology, 2013, 24, 452001.

3 D. S. Hecht, L. Hu and G. Irvin, Adv. Mater., 2011, 23, 14821513.

4 L. Y. L. Wu, W. T. Kerk and C. C. Wong, Thin Solid Films, 2013, 544, 427-432.

5 H. H. Khaligh and I. A. Goldthorpe, Nanoscale Res. Lett., 2014, 9, 310.

6 M. Song, D. S. You, K. Lim, S. Park, S. Jung, C. S. Kim, D.-H. Kim, D.-G. Kim, J.-K. Kim, J. Park, Y.-C. Kang, J. Heo, S.-H. Jin, J. H. Park and J.-W. Kang, Adv. Funct. Mater., 2013, 23, 4177-4184.

7 W. Gaynor, G. F. Burkhard, M. D. McGehee and P. Peumans, Adv. Mater., 2011, 23, 2905-2910.

8 Z. Yu, L. Li, Q. Zhang, W. Hu and Q. Pei, Adv. Mater., 2011, 23, 4453-4457.

9 W. Gaynor, S. Hofmann, M. G. Christoforo, C. Sachse, S. Mehra, A. Salleo, M. D. McGehee, M. C. Gather, B. Lüssem, L. Müller-Meskamp, P. Peumans and K. Leo, Adv. Mater., 2013, 25, 4006-4013.

10 Z. Yu, Q. Zhang, L. Li, Q. Chen, X. Niu, J. Liu and Q. Pei, Adv. Mater., 2011, 23, 664-668.

11 T. Kim, Y. W. Kim, H. S. Lee, H. Kim, W. S. Yang and K. S. Suh, Adv. Funct. Mater., 2013, 23, 1250-1255.

12 C. Celle, C. Mayousse, E. Moreau, H. Basti, A. Carella and J.-P. Simonato, Nano Res., 2012, 5, 427-433.

13 J. Lee, P. Lee, H. B. Lee, S. Hong, I. Lee, J. Yeo, S. S. Lee, T.-S. Kim, D. Lee and S. H. Ko, Adv. Funct. Mater., 2013, 23, 4171-4176.

14 B. Wiley, Y. Sun and Y. Xia, Langmuir, 2005, 21, 8077-8080.

15 B. Wiley, Y. Sun and Y. Xia, Acc. Chem. Res., 2007, 40, 10671076.

16 J.-Y. Kim and N. A. Kotov, Chem. Mater., 2014, 26, 134-152.

17 J.-Y. Lee, S. T. Connor, Y. Cui and P. Peumans, Nano Lett., 2008, 8, 689-692.

18 S. Ye, A. R. Rathmell, Z. Chen, I. E. Stewart and B. J. Wiley, Adv. Mater., 2014, 26, 6670-6687.

19 S. De, T. M. Higgins, P. E. Lyons, E. M. Doherty, P. N. Nirmalraj, W. J. Blau, J. J. Boland and J. N. Coleman, ACS Nano, 2009, 3, 1767-1774.

20 S.-E. Park, S. Kim, D.-Y. Lee, E. Kim and J. Hwang, J. Mater. Chem. A, 2013, 1, 14286-14293.

21 Y. Wang, T. Feng, K. Wang, M. Qian, Y. Chen and Z. Sun, J. Nanomater., 2011, 2011, 1-5.
22 T. L. Chen, D. S. Ghosh, V. Mkhitaryan and V. Pruneri, ACS Appl. Mater. Interfaces, 2013, 5, 11756-11761.

23 P. Lee, J. Lee, H. Lee, J. Yeo, S. Hong, K. H. Nam, D. Lee, S. S. Lee and S. H. Ko, Adv. Mater., 2012, 24, 3326-3332.

24 A. R. Madaria, A. Kumar, F. N. Ishikawa and C. Zhou, Nano Res., 2010, 3, 564-573.

25 S. Coskun, E. Selen Ates and H. E. Unalan, Nanotechnology, 2013, 24, 125202.

26 C. Sachse, L. Müller-Meskamp, L. Bormann, Y. H. Kim, F. Lehnert, A. Philipp, B. Beyer and K. Leo, Org. Electron., 2013, 14, 143-148.

27 E. C. Garnett, W. Cai, J. J. Cha, F. Mahmood, S. T. Connor, M. Greyson Christoforo, Y. Cui, M. D. McGehee and M. L. Brongersma, Nat. Mater., 2012, 11, 241-249.

28 T.-B. Song, Y. Chen, C.-H. Chung, Y. Yang, B. Bob, H.-S. Duan, G. Li, K.-N. Tu and Y. Huang, ACS Nano, 2014, 8, 2804-2811.

29 S. Yun, X. Niu, Z. Yu, W. Hu, P. Brochu and Q. Pei, Adv. Mater., 2012, 24, 1321-1327.

$30 \mathrm{H}$. Varela-Rizo, I. Martín-Gullón and M. Terrones, ACS Nano, 2012, 6, 4565-4572.

31 J. H. Yim, S.-Y. Joe, C. Pang, K. M. Lee, H. Jeong, J.-Y. Park, Y. H. Ahn, J. C. de Mello and S. Lee, ACS Nano, 2014, 8, 2857-2863.

32 F. S. F. Morgenstern, D. Kabra, S. Massip, T. J. K. Brenner, P. E. Lyons, J. N. Coleman and R. H. Friend, Appl. Phys. Lett., 2011, 99, 183307.

33 A. J. Stapleton, R. a. Afre, A. V. Ellis, J. G. Shapter, G. G. Andersson, J. S. Quinton and D. a. Lewis, Sci. Technol. Adv. Mater., 2013, 14, 035004.

34 M.-S. Lee, K. Lee, S.-Y. Kim, H. Lee, J. Park, K.-H. Choi, H.-K. Kim, D.-G. Kim, D.-Y. Lee, S. Nam and J.-U. Park, Nano Lett., 2013, 13, 2814-2821.

35 I. N. Kholmanov, M. D. Stoller, J. Edgeworth, W. H. Lee, H. Li, J. Lee, C. Barnhart, J. R. Potts, R. Piner, D. Akinwande, J. E. Barrick and R. S. Ruoff, ACS Nano, 2012, 6, 5157-5163.

36 K. Naito, N. Yoshinaga, E. Tsutsumi and Y. Akasaka, Synth. Met., 2013, 175, 42-46.

37 B.-T. Liu and H.-L. Kuo, Carbon, 2013, 63, 390-396.

38 D.-S. Leem, A. Edwards, M. Faist, J. Nelson, D. D. C. Bradley and J. C. de Mello, Adv. Mater., 2011, 23, 4371-4375.

39 W. A. Macdonald, J. Mater. Chem., 2004, 4-10.

40 H. Zhu, Z. Xiao, D. Liu, Y. Li, N. J. Weadock, Z. Fang, J. Huang and L. Hu, Energy Environ. Sci., 2013, 6, 2105-2111. 41 V. Zardetto, T. M. Brown, A. Reale and A. Di Carlo, J. Polym. Sci. Part B Polym. Phys., 2011, 49, 638-648.

42 C.-J. Ni and F. Chau-Nan Hong, RSC Adv., 2014, 4, 4033040338.

43 C.-H. Chung, T.-B. Song, B. Bob, R. Zhu and Y. Yang, Nano Res., 2012, 5, 805-814.

44 S. J. Henley, M. Cann, I. Jurewicz, A. Dalton and D. Milne, Nanoscale, 2014, 6, 946-952.

45 G. Szakonyi and R. Zelkó, Int. J. Pharm. Invest., 2012, 2, 1825. 
46 S. Bhattacharya, D. K. Sharma, S. Saurabh, S. De, A. Sain, A. Nandi and A. Chowdhury, J. Phys. Chem. B, 2013, 117, 7771-7782.

47 J. Teng, S. Bates, D. A. Engers, K. Leach, P. Schields and Y. Yang, J. Pharm. Sci., 2010, 99, 3815-3825.

48 B. C. Hancock and G. Zografi, Pharm. Res., 1994, 11, 471-477. 49 C. Wood, Chem. Unserer Zeit, 2002, 2002, 44-52.

50 A. Göthlich, S. Koltzenburg and G. Schornick, Chem. unserer Zeit, 2005, 39, 262-273.

51 M. J. Root and S. Bohac, J. Soc. Cosmet. Chem., 1966, 17, 595606.

52 S. Yoshioka and Y. Aso, J. Pharm. Sci., 2007, 96, 960-981.

53 F. Selzer, N. Weiß, L. Bormann, C. Sachse, N. Gaponik, L. Müller-Meskamp, A. Eychmüller and K. Leo, Org. Electron., 2014, 15, 3818-3824.

54 S. Zhu, Y. Gao, B. Hu, J. Li, J. Su, Z. Fan and J. Zhou, Nanotechnology, 2013, 24, 335202.

55 P. Peng, A. Hu, H. Huang, A. P. Gerlich, B. Zhao and Y. N. Zhou, J. Mater. Chem., 2012, 22, 12997-13001.

56 S. Karim, M. Toimil-Molares, A. Balogh, W. Ensinger, T. Cornelius, E. Khan and R. Neumann, Nanotech, 2006, 17, 5954-5959.

57 J. Jiu, M. Nogi, T. Sugahara, T. Tokuno, T. Araki, N. Komoda, K. Suganuma, H. Uchida and K. Shinozaki, J. Mater. Chem., 2012, 22, 23561-23567.
58 A. R. Madaria, A. Kumar and C. Zhou, Nanotechnology, 2011, 22, 245201.

59 C. Yang, H. Gu, W. Lin, M. M. Yuen, C. P. Wong, M. Xiong and B. Gao, Adv. Mater., 2011, 23, 3052-3056.

60 J. Jiu, T. Sugahara, M. Nogi, T. Araki, K. Suganuma, H. Uchida and K. Shinozaki, Nanoscale, 2013, 5, 1182011828.

61 C. Mayousse, C. Celle, E. Moreau, J.-F. Mainguet, A. Carella and J.-P. Simonato, Nanotechnology, 2013, 24, 215501.

62 S. S. K. Dong Yun Choi, H. W. Kang and H. J. Sung, Nanoscale, 2013, 5, 977-983.

63 Y. Lee, J.-R. Choi, K. J. Lee, N. E. Stott and D. Kim, Nanotechnology, 2008, 19, 415604.

64 X.-Y. Zeng, Q.-K. Zhang, R.-M. Yu and C.-Z. Lu, Adv. Mater., 2010, 22, 4484-4488.

65 W. Hu, X. Niu, R. Zhao and Q. Pei, Appl. Phys. Lett., 2013, 102, 083303.

66 T. Akter and W. S. Kim, ACS Appl. Mater. Interfaces, 2012, 4, 1855-1859.

67 R. M. Mutiso, M. C. Sherrott, A. R. Rathmell, B. J. Wiley and K. I. Winey, ACS Nano, 2013, 7, 7654-7663.

68 C. Mayousse, C. Celle, A. Fraczkiewicz and J.-P. Simonato, Nanoscale, 2015, 7, 2107-2115. 